\title{
Genetic diversity of Triatoma infestans (Hemiptera: Reduviidae) in Chuquisaca, Bolivia based on the mitochondrial cytochrome b gene
}

\author{
Rosanna Giordano, Juan Carlos Pizarro Cortez**/+ , Stephanie Paulk*, Lori Stevens*
}

Department of Plant and Soil Science *Department of Biology, University of Vermont, Burlington, VT 05405 US **Facultad de Bioquímica, Universidad de San Francisco Xavier, Sucre, Bolivia

Partial cytochrome $b$ DNA sequences for 62 Triatoma infestans were analyzed to determine the degree of genetic variation present in populations of this insect in the northwest region of Chuquisaca, Bolivia. A total of seven haplotypes were detected in the localities sampled. The phylogenetic relationship and population genetic structure of the haplotypes found in this region, indicate that there is greater variation in this relatively small region of Bolivia than what has been previously reported by studies using the same gene fragment, for more distant geographic areas of this country. In addition, a comparison of rural and peri-urban localities, indicate that there is no difference in the genetic variation of $\mathrm{T}$. infestans between these two environments.

Key words: Triatoma infestans - Trypanosoma cruzi - Chagas disease - cytochrome b - genetic diversity - Bolivia

Triatoma infestans is the most widespread vector of Trypanosoma cruzi, the causative agent of Chagas disease in South America. A public health program, the Southern Cone Initiative, launched in 1991 reduced the prevalence of Chagas disease in most South American countries by targeting transmission by insect vectors and blood transfusion. Between 1997 and 2000 Argentina, Brazil, Chile, Paraguay, and Uruguay reduced prevalence by 60 $90 \%$ with a current low prevalence of $0.06 \%$ in Uruguay to a high of 3.9\% in Paraguay (Moncayo 2003). In contrast, infection prevalence in Bolivia remains high in the general population (28.8\%), with the highest prevalence in children under five years of age in Cochabamba (22\%), and in Chuquisaca (35\%) (Moncayo 2003, Pizarro unpublished data). The results of several studies indicate that in rural endemic areas, active transmission of T. cruzi occurs at any age (Pless et al. 1992, Wincker et al. 1997, Brenière et al. 2002).

Control of the parasite is hampered by the complex ecology of its transmission. T. cruzi has multiple mammalian hosts and insect vectors. Non-human mammal hosts include dogs, domestic and wild guinea pigs and various peri-domestic animals such as goats, sheep, and pigs. Vector populations, with the potential for transmission, can be found in domestic environments, where they feed on dogs and guinea pigs kept in homes, in peri-domestic homestead associations, and in sylvatic zones associated with wild guinea pigs. In Argentina, Brazil, Chile, and Uruguay, T. infestans is exclusively domestic or peri-domestic, thus eradication of the vector in these habitats,

Financial support: URECA, HELIX, VT EPSCoR EPS 0236976

${ }^{+}$Corresponding author. E-mail: jpizzaro@uvm.edu

Received 8 November 2004

Accepted 21 October 2005 followed by vigilance against re-infestation, has proven largely successful in reducing transmission of $T$. cruzi and thus the prevalence of Chagas disease. In contrast, in Bolivia the vectors occur in domestic, peri-domestic, and sylvatic environments. Thus, control of T. infestans in towns and homesteads is confounded by the possible re-infestation from surrounding sylvatic areas. In addition, recent work in peridomestic sites in Argentiana has shown that spraying with pyrethroids does not always eradicate $T$. infestans and that infestations present a year after spraying resulted from individuals that had survived treatment (Gürtler et al. 2003). Audino et al. (2004) have shown that higher activities of degradative esterases and P450 contribute to deltamethrin resistance.

It has been suggested that the Cochabamba valley, to the north of Chuquisaca, is the geographic origin and epicenter of spread of T. infestans (Torrico 1946, Schofield 1988). However, Dujardin et al. (1998) sampled from the Sucre region of Chuquisaca using allozymes, and in a comparison with other Andean and non-Andean regions determined that the Sucre-Vallegrande-Potosi area is the center of origin and dispersion of $T$. infestans. We conducted a study over a larger area within Chuquisaca using a fragment of the mitochondrial cytochrome $b$ gene, as in Monteiro et al. (1999), for 62 specimens from periurban and rural localities in order to ascertain the population structure of $T$. infestans in this region and determine whether cyt $b$ is a useful marker for this purpose.

Evolutionary theory predicts higher genetic variation in ancestral sylvatic populations than in recently derived domestic populations, and in domestic populations that intermix with sylvatic populations (Schofield \& Dias 1999). If the Cochabamba Valley, the neighboring Department of Chuquisaca or both are the geographic origin and epicenter of spread of T. infestans, insects collected in these regions should display more genetic variation. On the other hand, populations of $T$. infestans, which are highly adapted to domestic environment may show less genetic variation as a result of human dissemination. 


\section{MATERIALS AND METHODS}

Insect collections - Insects originated from the provinces of Oropeza, Zudañez, Azurduy, Yamparaez, and Tomina within the Department of Chuquisaca, Bolivia (Table I). We collected and sequenced a total of 62 insects from 30 localities in both peri-urban and rural settings. We also sequenced one specimen from the US/ CDC colony that originated in Argentina. Peri-urban is defined as inhabited areas in the immediate vicinity of a city. Rural sites are differentiated as rural concentrated, between 2000 and 10,000 inhabitants and rural dispersed with less than 2000 inhabitants (Table I). Localities sampled had not been sprayed with insecticides for at least three years. Insects were a mixture of nymphs and adults and were collected from inside as well as the immediate vicinity of homes. Insects from localities with more than one specimen may have been obtained from several houses. Collections were made in the months of the Southern hemisphere summer and spring of 2002 and fall of 2003. Insects from the first collection in Zudañez were frozen live. Those from subsequent collections as well as the CDC colony specimen were placed in 95\% ethanol while alive.

Molecular analysis - DNA was extracted using four legs from a given specimen using the Qiagen DNeasy DNA extraction kit (Qiagen, Inc., Valencia, CA). Extracted DNA was amplified via PCR using $10 \mu \mathrm{M}$ cytochrome b F and R primers (Lyman et al. 1999) and Ready to go PCR beads (Amersham Bioscience, Piscataway, NJ) with the following protocol: $95^{\circ} \mathrm{C} 2 \mathrm{~min}\left(95^{\circ} \mathrm{C} 30 \mathrm{~s} ; 50^{\circ} \mathrm{C} 30 \mathrm{~s} ; 72^{\circ} \mathrm{C}\right.$ 30 s) 40X. PCR products were cleaned using the Qiagen PCR cleaning kit (Qiagen, Inc.). DNA concentration was measured using a Nanodrop 1000 spectrophotometer (Nanodrop, Bethesda, MD). PCR products were sequenced directly and in both directions, using ABI Big Dye sequencing mix version $3.1 ; 2 \mu \mathrm{M}$ cyt $\mathrm{b} F$ or $\mathrm{R}$ primers and the following protocol: $95^{\circ} \mathrm{C} 3 \min \left(98^{\circ} \mathrm{C} 10 \mathrm{~s} ; 50^{\circ} \mathrm{C} 5\right.$ $\left.\mathrm{s} ; 60^{\circ} \mathrm{C} 4 \mathrm{~min}\right) 30$. Sequencing reactions were cleaned using Sephadex G50 columns and run on an ABI 3100 sequencer (AB, Foster City, CA). Sequences were analyzed using the Sequencher 3.1 (ABI) and aligned by hand using PAUP v4.0b10 (Swofford 2002). A fragment of $411 \mathrm{bp}$ with no insertions or deletions was used in the analysis. Relationships among haplotypes were estimated using parsimony and maximum likelihood. Maximum parsimony trees were identified using branch and bound. For the likelihood analysis the GTR + G + I model of sequence evolution was chosen based on the results of model analysis in Modeltest (v3.6 PPC) (Posada \& Crandall 1998). The model parameters estimated by Modeltest were transferred to PAUP and the likelihood search was performed using 30 iterations of random additions of taxa. Bootstrap node support in the parsimony analysis was estimated using branch and bound, and 1000 replicates. Decay indices were calculated following Bremer $(1988,1994)$. Bremer support values for the parsimony tree were calculated by saving all trees one step longer than the most parsimonious tree. Bootstrap values for the likelihood analysis are based on 350 replicates using the heuristic search with 5 iterations each. We calculated haplotype diversity for regions with at least two haplotypes, ac- cording to the formula $h=\left(1-\Sigma X_{i}^{2}\right) n / n-1$, where $X$ is the frequency of a haplotype and $\mathrm{n}$ is the sample size (Nei \& Tajima 1981). The haplotype network is the estimated 95\% plausible set of cladograms obtained for cyt $b$ haplotypes and was constructed using the software package TCS (Clement et al. 2000). Comparison of the rural vs periurban and of Andean vs non-Andean samples by F statistics was done using the software Arlequin (Schneider et al. 2001). Two sequences obtained from Genbank (AF045730, AF045721; Lyman et al. 1999) as well as five sequences not listed in Genbank but originating from Monteiro et al. (1999), and obtained directly from the author were used as comparison to the haplotypes we obtained and to construct the phylogenetic tree. Haplotype sequences have been submitted to Genbank and can be retrieved using the following accession numbers AY702018-AY702024.

\section{RESULTS}

Sixty-two T. infestans were sampled from 30 localities in five provinces of the Department of Chuquisaca. Seven haplotypes whose distribution by locality is shown in Table I and Fig. 1 were detected. Haplotype A has the widest distribution and occurs in four of the five provinces. This haplotype was also detected in a specimen from a colony maintained at the CDC in Atlanta, GA, whose founders were originally collected in Formosa, Argentina. Haplotype B, the second most common haplotype, was found in the regions of Yamparaez, Zudañez, and Tomina but not in Oropeza, or Azurduy. Haplotype $\mathrm{C}$ was found in Oropeza and Azurduy. The remaining haplotypes D, E, $\mathrm{F}$, and $\mathrm{G}$ were unique to Oropeza. The greatest number of haplotypes (6 of 7), were found in the province of Oropeza. Four of the six haplotypes were found in the capital city of Sucre and its environs. The regions of Zudañez, Yamparaez, and Azurduy each had two haplotypes (Table II). The seven haplotypes are very similar to each other, differing only in 1-4 base pairs (bp) (Table II). Not surprisingly, all variable sites are transitions on third or first codon positions and do not result in amino acid replacements. The only substitution on first codon position (site 595 in haplotype G), changes codon TTA found in all the other 164 haplotypes to CTA; both codons code for leucine (alignment was based on the cytochrome $\mathrm{b}$ sequence of T. dimidiata NC 002609). The haplotype diversity indices (Nei \& Tajima 1981) for the different regions sampled are: Oropeza $h=0.41$; Zudañez $h=0.51$; Yamparaez $h=$ 0.29; Azurduy h $=0.67$ (Table II).

We compared T. infestans populations, using haplotype frequencies, according to the type of location they were collected, i.e. rural-concentrated and dispersed vs peri-urban and Andean vs non-Andean. The identity alleles between rural-concentrated and rural-dispersed (Fst $=-0.004, \mathrm{P}>0.05)$ as well as both rural types and peri-urban localities $(\mathrm{Fst}=0.05, \mathrm{P}>0.05$; Fst $=0.07$, $\mathrm{P}>0.05$ ) is not significant. The comparison of haplotype frequencies between Andean and previously published non-Andean populations (Monteiro et al. 1999) shows that the number of alleles found in the two regions do not differ. However, there are differences in the particular alleles found in the Andean and non-Andean regions (Fst 
TABLE I

Cytochrome b haplotypes found in specimens of Triatoma infestans sampled in the Department of Chuquisaca, Bolivia and listed in accordance to their location, type of locality, and number

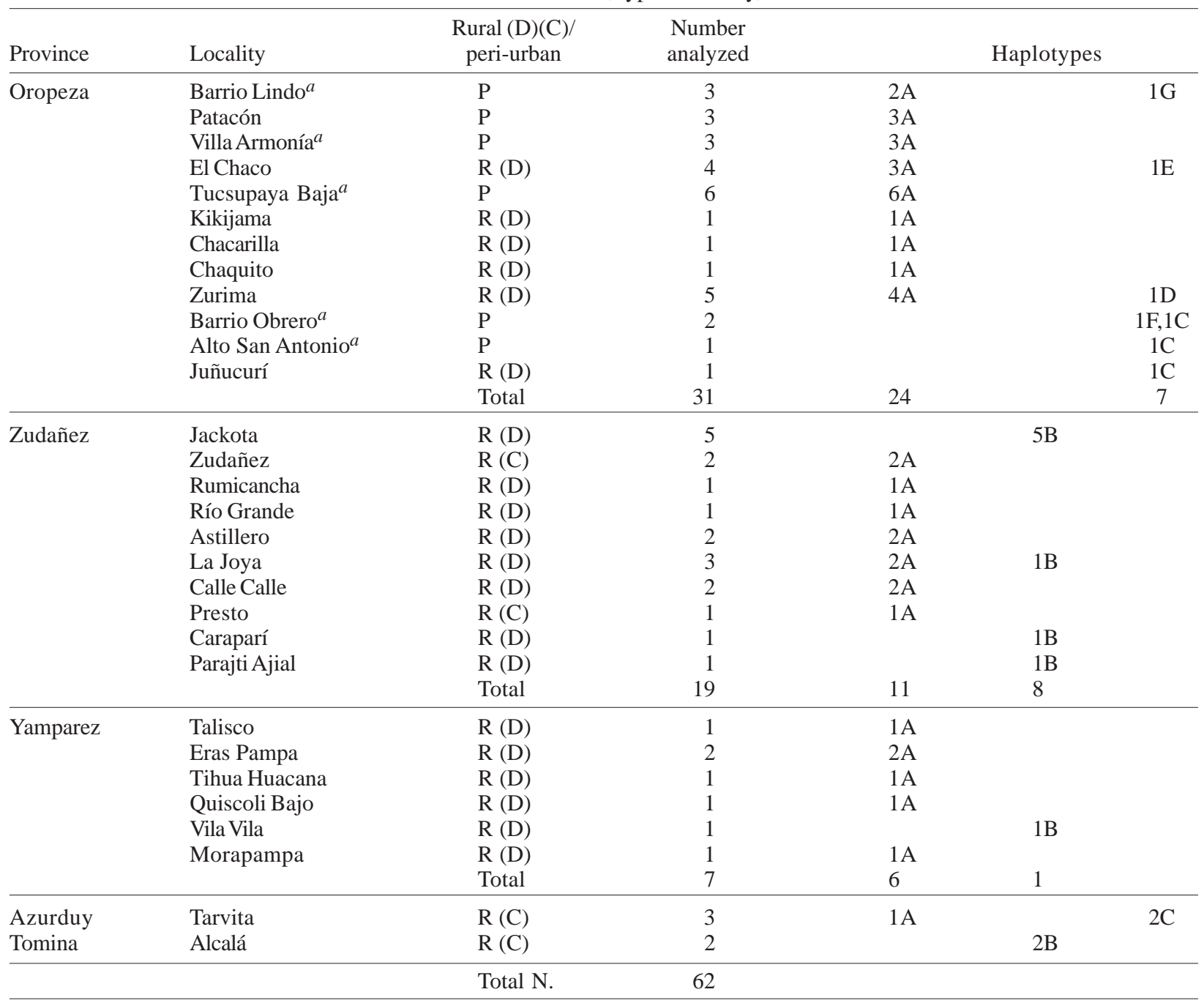

$a$ : peri-urban localities of Sucre; C: concentrated, between 2000 and 10,000 inhabitants; D: dispersed, less than 2000 inhabitants.

$=0.36, \mathrm{P}<0.00001)$ (Table III).

There are no differences in base composition between haplotypes of the in-group or between the in- and outgroups, although there is a slight AT bias (64\%).

Parsimony analysis results in 19 equally short trees (Fig. 2A), whereas the likelihood analysis found a single tree (Fig. 2B). The likelihood tree is identical to one of the most parsimonious trees. Both the parsimony and likelihood analyses support three groups. The three haplotypes from Brazil form a clade well supported in the parsimony analysis but not in the likelihood analysis. The clade containing haplotype $\mathrm{C}$ and BOL-SA is weakly supported in both the parsimony and likelihood tree. The remaining haplotypes (B, D, E, F, and BOL-DM) differ in 1-2 base pairs (bp) and their relationship is not resolved (Fig. 2). Haplotypes B, C, D, E, and F share two transitions of a guanine to adenine at positions 741 and 789 (Table II).
The consensus tree supports the conclusion that the T. infestans haplotypes from Brazil form a distinct clade. The bootstrap value for this clade is high (Fig. 2). There is also good support for the clade formed by haplotypes $\mathrm{A}$ and $\mathrm{G}$ and the single colony specimen from the CDC. Haplotypes A and G segregate separately from the others because they do not posses the nucleotide substitutions at positions 741 and 789 shared by the other remaining haplotypes, B, C, D, E, F. However the remaining difference between the latter haplotypes are too few, 1-2 bp, to permit resolution using parsimony analysis (Fig. 2).

The relationships among haplotypes are also shown in the haplotype network (Fig. 3). Haplotype D is indicated as the possible common ancestor for the clade. Haplotype C, previously the only haplotype found in the Andean region (Monteiro et al. 1999), was found in five individuals sampled from Oropeza and Azurduy. Haplotype A, was found in $68 \%$ of the individuals from 


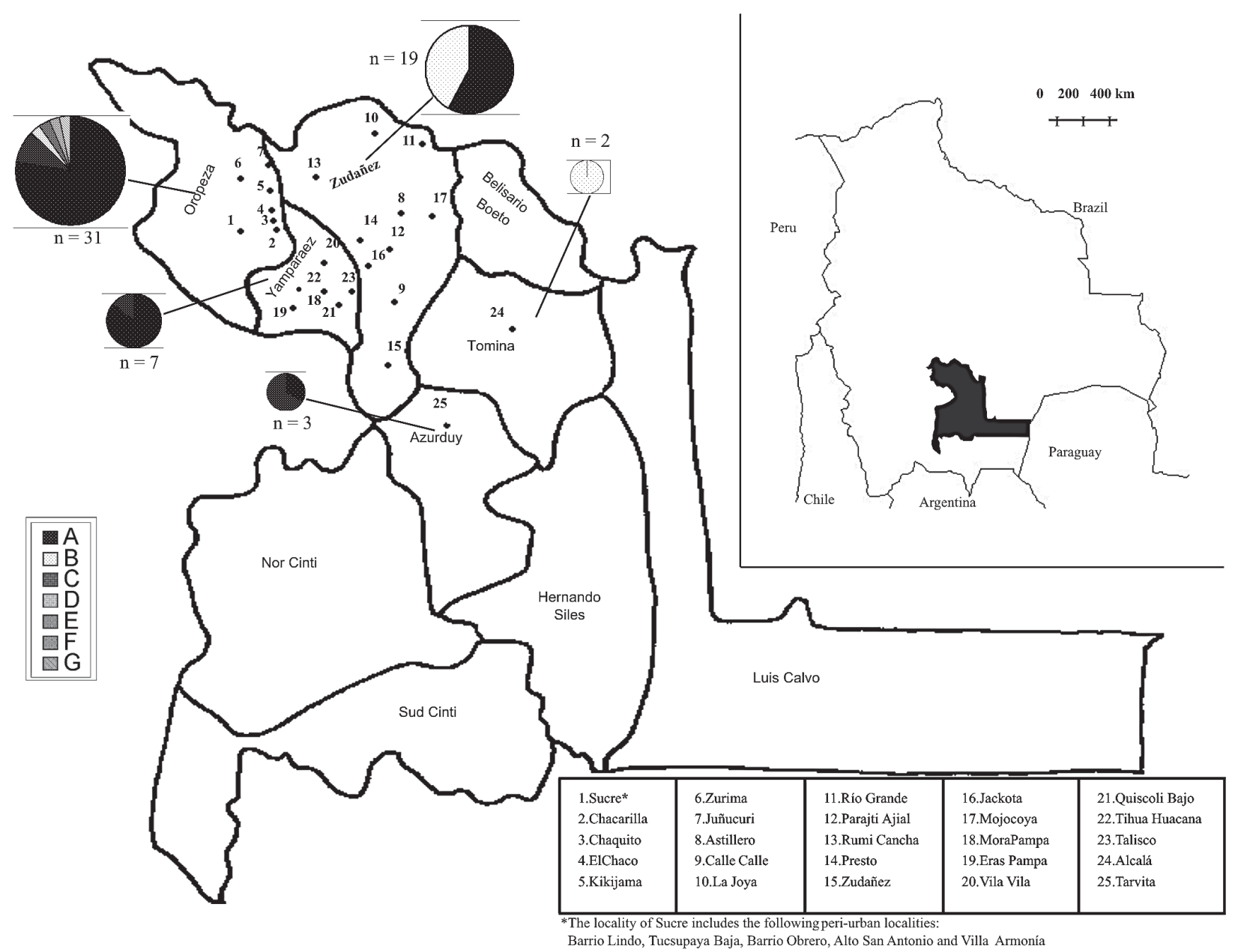

Fig. 1: collection localities and distribution of cyt $\mathrm{b}$ haplotypes for Ttiatoma infestans, in five of the provinces of the Department of Chuquisaca, Bolivia.

\section{TABLE II}

Variable sites found in a $411 \mathrm{bp}$ fragment of the cytochrome b gene in 62 Triatoma infestans specimens sampled in Chuquisaca, Bolivia, and measure of haplotype diversity for the regions of Oropeza (1), Zudañez (2),

Yamparaez (3), Azurduy (4), and Tomina (5)

\begin{tabular}{|c|c|c|c|c|c|c|c|c|c|c|c|c|c|c|c|}
\hline \multirow[b]{2}{*}{ Haplotype } & \multirow[b]{2}{*}{ Number } & \multicolumn{9}{|c|}{ Variable sites } & \multicolumn{5}{|c|}{ Province } \\
\hline & & 501 & 537 & 595 & 633 & 657 & 738 & 741 & 747 & 789 & 1 & 2 & 3 & 4 & 5 \\
\hline A & 42 & A & $\mathrm{C}$ & $\mathrm{T}$ & A & $\mathrm{T}$ & A & G & $\mathrm{T}$ & $\mathrm{G}$ & 24 & 11 & 6 & 1 & 0 \\
\hline B & 11 & & $\mathrm{~T}$ & & & & & A & & A & 0 & 8 & 1 & 0 & 2 \\
\hline $\mathrm{C}$ & 5 & $\mathrm{G}$ & & & & & & A & & $\mathrm{A}$ & 3 & 0 & 0 & 2 & 0 \\
\hline D & 1 & & & & & & & A & & A & 1 & 0 & 0 & 0 & 0 \\
\hline E & 1 & & & & & $\mathrm{C}$ & & A & & A & 1 & 0 & 0 & 0 & 0 \\
\hline $\mathrm{F}$ & 1 & & & & & & G & $\mathrm{A}$ & $\mathrm{C}$ & A & 1 & 0 & 0 & 0 & 0 \\
\hline G & 1 & & & $\mathrm{C}$ & $\mathrm{G}$ & & & & & & 1 & 0 & 0 & 0 & 0 \\
\hline \multicolumn{9}{|c|}{ Haplotype diversity: $\mathrm{h}=\left(1-\Sigma \mathrm{X}_{\mathrm{i}}^{2}\right) \mathrm{n} / \mathrm{n}-1$} & 0.4 & 0.5 & 0.3 & 0.7 & 0 & & \\
\hline
\end{tabular}

Chuquisaca and is distributed in all the regions we sampled with the exception of Tomina. Two other lineages, found by previous studies, branch from haplotype $\mathrm{D}$, they are the single haplotype found in the Bolivian Chaco (BOLDM) and the specimens from Brazil and Argentina (Monteiro et al. 1999, Lyman et al. 1999). The specimen from the CDC colony, founded with individuals collected from Argentina was identified as haplotype A, the most common haplotype in Chuquisaca.

\section{DISCUSSION}

The present study detected higher levels of genetic diversity in what is a relatively small region of Bolivia, than levels previously reported using the same genetic 
TABLE III

Measure of genetic diversity between rural-concentrated and dispersed vs peri-urban and Andean and non-Andean populations in Chuquisaca, Bolivia

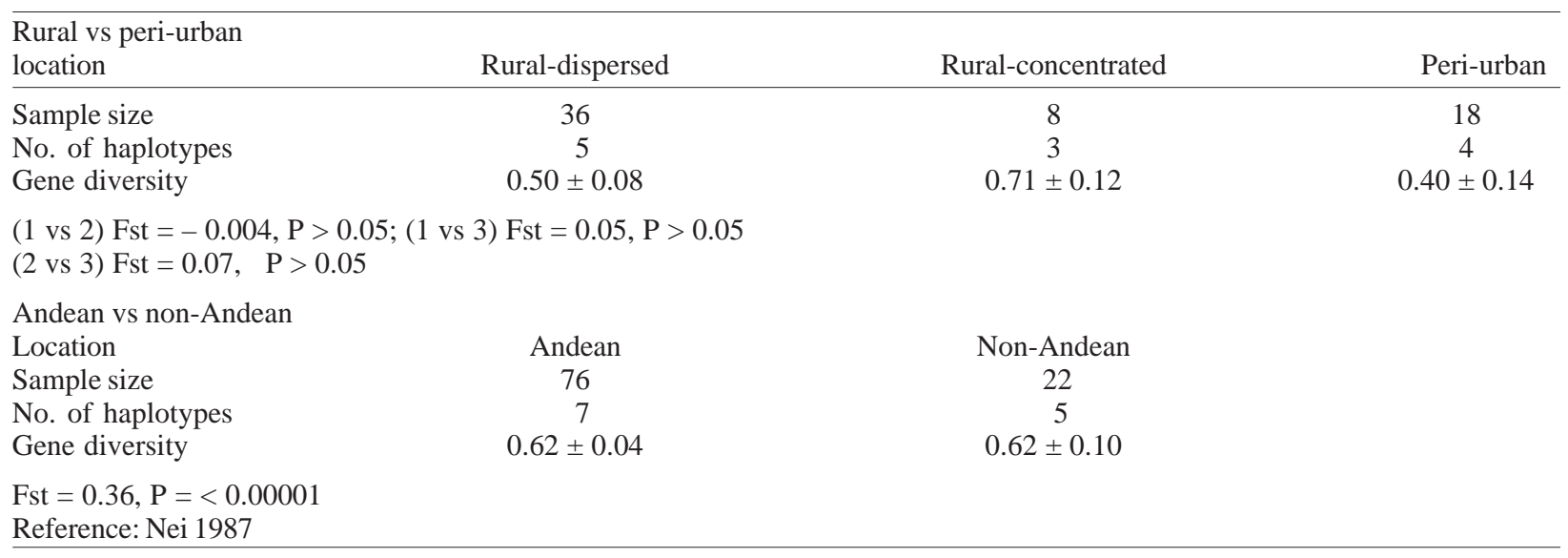

A

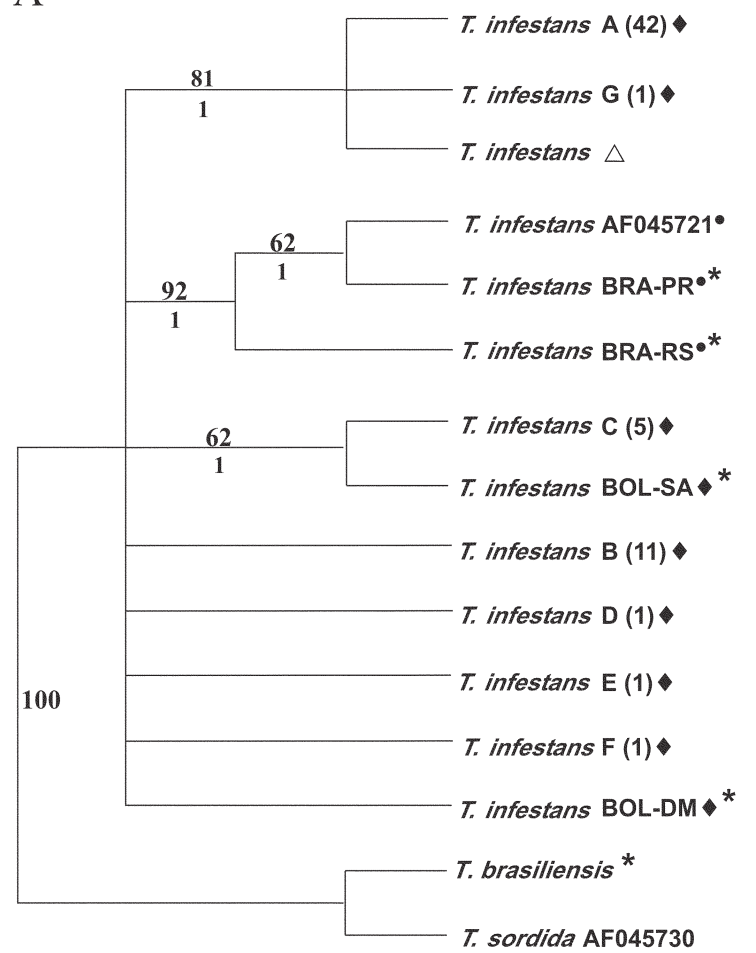

B

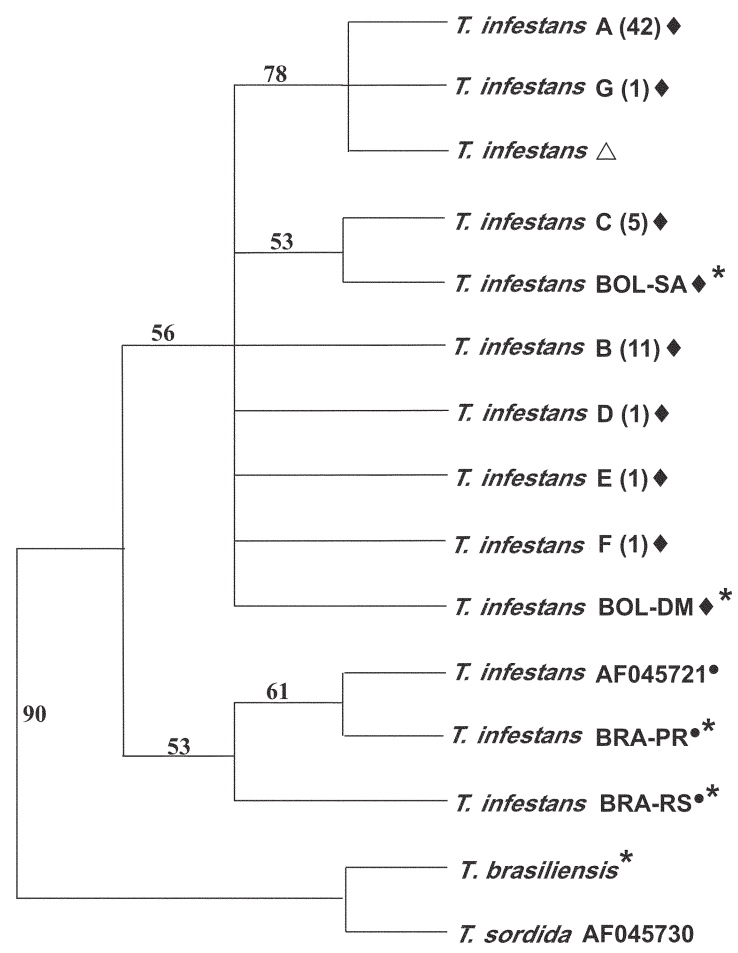

Fig. 2: strict consensus of 19 most parsimonious (A) and 1 likelihood (B) tree for cyt b haplotypes found in Triatoma infestans. Trees were rooted using $T$. brasilensis and $T$. sordida.

Numbers above nodes are bootstrap values, numbers below nodes are Bremer support values. The likelihood tree was estimated using the GTR $+\mathrm{I}+\mathrm{G}$ model $(\alpha=0.41)$. Number of individuals of each haplotype are in parenthesis. Argentina $=\Delta$, Bolivia $=\bullet$, Brazil $=\bullet$. *Indicates sequences from Monteiro et al. (1999).

marker in two distantly located sites in Bolivia. Monteiro et al. (1999), sampled in Cochabamba, Bolivia (six sylvatic specimens from one locality, and eight domestic specimens from three different localities), and the southern Chaco region (four specimens from one sylvatic locality). Analysis of those samples showed that both sylvatic and domestic specimens in Cochabamba shared one haplotype, which was different from the single haplotype found in the four sylvatic specimens from the Chaco region to the south. In our study the greatest haplotype diversity was found in the region of Azurduy $h=0.67$, where we sampled three specimens and found two haplotypes (Table II), but the greatest number of haplotypes, (six of a total of seven), were detected in the region of Oropeza. Our data indicate that haplotype A is the most widespread, and that it has a greater prevalence in the northwest re- 


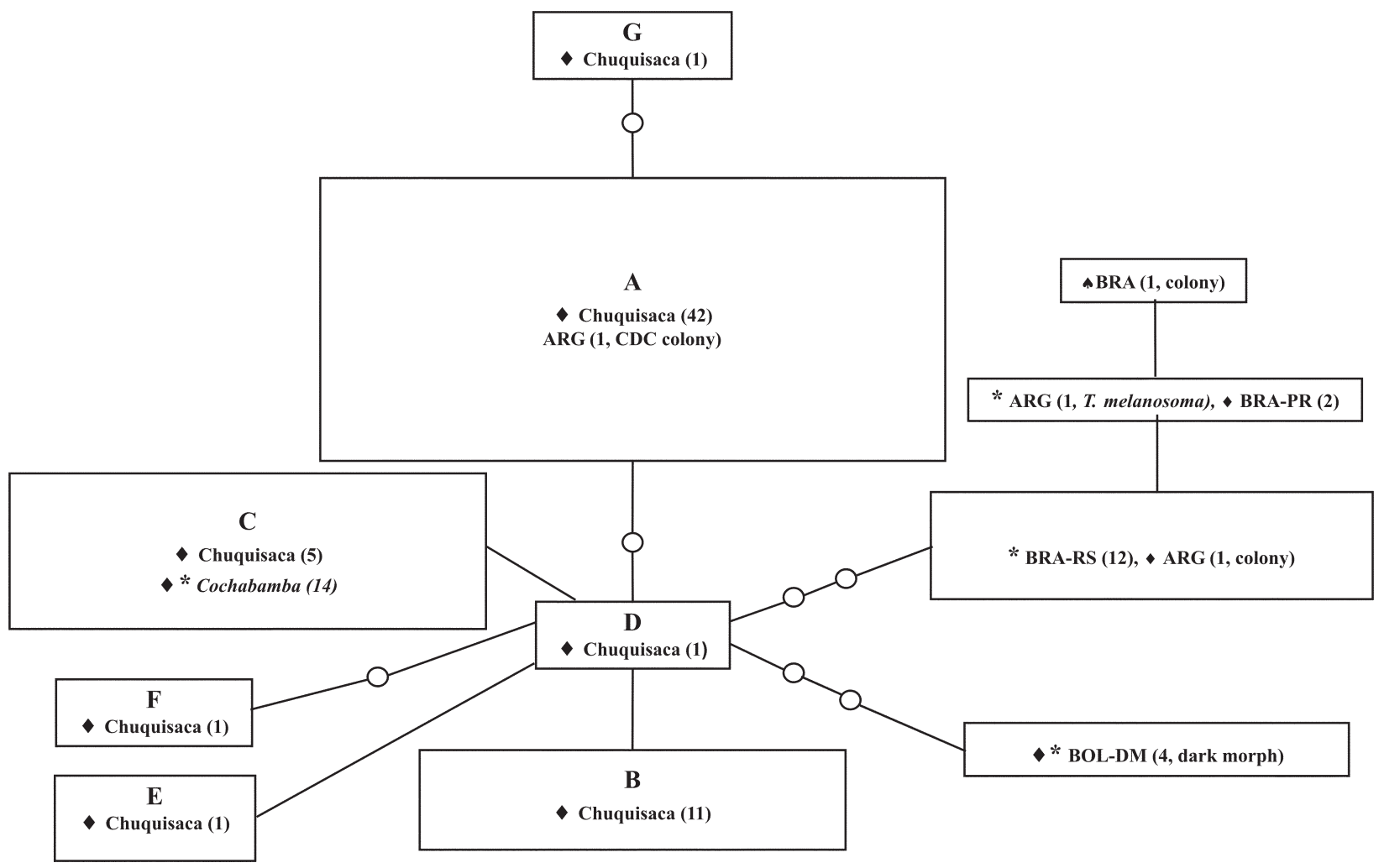

Fig. 3: unrooted gene tree for Triatoma infestans cyt $\mathrm{b}$ haplotypes from this and previously published studies. The haplotype network is the estimated $95 \%$ plausible set of cladograms using TCS software. Bars represent parsimonious connections between haplotypes with a probability higher than $95 \%$ with each representing one mutational step. Intermediate haplotypes missing in the sample are represented by "0". Localities sampled in, Bolivia. Haplotypes* from Monteiro et al. (1999) and Lyman et al. (1999). ARG-Argentina; BOLBolivia; BRA-Brazil.

gion of Chuquisaca, mainly in the provinces of Oropeza and Yamparaez. Haplotype B is more commonly found in the northeast and haplotype $\mathrm{C}$ in the central region of the Department of Chuquisaca (Fig. 1). Given the considerable lower number of samples from Tomina and Azurduy, in comparison to the other three regions, it is difficult to make conclusive statements regarding the actual distribution of some haplotypes, however our present data suggest that there may be structure in the distribution of the cyt b haplotypes in the region of Chuquisaca.

Our results concur with those of Dujardin et al. (1998) who found higher allozyme variation in the Sucre-PotosiVallegrande triangle compared to seven other sites in Bolivia, as well as Peru, Brazil, and Uruguay.

The haplotype network identifies haplotype D as ancestral even though it was found in a single individual from Zurima, Oropeza. It is possible that haplotype A, the most widespread form of those sampled, is highly adapted to domestic environments, and that its distribution has been facilitated by humans.

It is of interest that four of the six haplotypes found in Oropeza occur in the region of Sucre and its environs. Moreover, two of these haplotypes were unique to Sucre $(F, G)$. The higher number of haplotypes in the Sucre region may point to this area as the origin of spread for this species or may be partially the result of human migra- tion from rural areas and the concomitant importation of T. infestans. The region of Chuquisaca as a whole has seen population shifts from rural to urban settings in recent historic time; in 1950 in Bolivia the population distribution between urban and rural areas was $17.61 \%$ and $82.39 \%$ respectively, whereas in 2001 the distribution was $41.04 \%$ urban and $58.96 \%$ rural (INE 2002). The area surrounding Sucre is highly disturbed and unlikely to support wild guinea pig populations. However, sylvatic populations of T. infestans could occur in the more distant rural region surrounding Sucre and be transported to the city area by humans. The region of Chuquisaca includes areas in the Bolivian Chaco and areas where wild populations of guinea pigs occur. This environmental setting suggests that sylvatic populations of $T$. infestans might also be present in the region of Chuquisaca and in fact have been reported in the literature (Torrico 1946, Noireau et al. 2005).

It is of interest that two haplotypes were found from the sampling of three specimens from Tarvita, Azurduy. This high number relative to sampling size may be indicative of a higher genetic variation in the T. infestans of this region. Tarvita is located close to the Chaco region, where sylvatic populations of $T$. infestans have been found and it is also on the migration path that humans have followed 
from the Chaco region to the Northern regions of Chuquisaca.

The migration of people from rural to peri-urban localities and major urban centers and the associated movement of T. infestans, may explain the lack of genetic diversity between rural and peri-urban localities detected by this study.

Our analysis supports the conclusion of previous studies (Monteiro et al. 1999, Panzera et al. 2004) that there is a difference in the haplotypes present in Andean and non-Andean localities. Bolivia is believed to be the purported point of origin and epicenter of the spread of $T$. infestans (Schofield 1988). Evidence of Chagas disease from mummified remains dated from around $2500 \mathrm{BC}$ in the North of Chile, indicate that this region was infested with $T$. infestans early on, possibly when Wankarani Indians migrated from the Bolivian altiplano. Thus T. infestans spread early along the western coast of South America, but reports of T. infestans in Brazil did not surface until the early 1900s (Schofield 1988). Brazilian populations of T. infestans were most likely founded by very few individuals. The lapse of time as well as their isolation from the ancestral populations in Bolivia can readily explain the difference in haplotypes found in these two regions.

The discrepancies in the level of genetic variation between this study and that of Monteiro et al. (1999), may indicate that the genetic diversity of T. infestans in different regions of Bolivia is influenced by local and unique geographic, ecological, and insect evolution or population histories. Most studies done to date in Bolivia have involved the sampling of fewer localities, this study indicates that increasing the number of sampling sites uncovers the presence of a higher degree of population diversity in T. infestans populations in Bolivia than what has been detected thus far. Moreover, as proposed by Noireau et al. (2005) it is of necessity to ascertain the degree of gene flow between domestic and wild populations of T. infestans in the regions of Bolivia where sylvatic populations have been documented.

We have found the cyt $b$ gene to be a useful marker of genetic diversity of $T$. infestans in the region of Chuquisaca. However, microsatellites would be a more sensitive and effective means to discern the population structure of $T$. infestans as well as a better means to follow the spread of this vector, tracking sources of re-infestations subsequent to insecticide spraying campaigns, and movement of vectors from sylvatic to domestic and peri-domestic habitats.

\section{ACKNOWLEDGEMENTS}

To G Bress for support. J Schall for comments on the manuscript and CW Kilpatrick and FN Soto-Adames for assistance with the analysis and comments on the manuscript. CB Beard for T. infestans colony specimens and FA Monteiro for cyt $\mathrm{b}$ sequences (BOL-SA, BOL-DM, BRA-PR, BRA-RS, and T. brasiliensis, Fig. 2).

\section{REFERENCES}

Audino PG, Vassena C, Barrios S, Zerba E, Picollo MI 2004. Role of enhanced detoxification in a deltamethrin-resistant population of Triatoma infestans (Hemiptera, Reduviidae) from Argentina. Mem Inst Oswaldo Cruz 99: 335-339.

Bremer K 1988. The limits of amino acids sequence data in angiosperm phylogenetic reconstruction. Evolution 42: 795803.

Bremer K 1994. Branch support and tree stability. Cladistics 10: 295-304.

Breniere SF, Bosseno MF, Noireau F, Yacsik N, Liegeard P, Aznar C, Hontebeyrie M 2002. Integrate study of a Bolivian population infected by Trypanosoma cruzi, the agent of Chagas disease. Mem Inst Oswaldo Cruz 97: 289-295.

Clement M, Posada D, and Crandall KA 2000. TCS: a computer program to estimate gene genealogies. Mol Ecol 9: 1657-1659.

Dujardin JP, Schofield CJ, Tibayrenc M 1998. Population structure of Andean Triatoma infestans: allozyme frequencies and their epidemiological relevance. Med Vet Entomol 12: 20-29.

Gurtler RE, Canale DM, Spillman C, Stariolo R, Salomon OD, Blanco S, Segura EL 2003. Effectiveness of residual spraying of peridomestic ecotopes with deltamithrin and permethrin on Triatoma infestans in rural western Argentina: a district-wide randomized trial. Bull WHO 82: 196205.

INE-Instituto Nacional de Estadística 2002. Censo Nacional de Población y Vivienda, 2001. Resultados Finales. La Paz, Bolivia.

Lyman ED, Monteiro FA, Escalante AA, Cordon-Rosales C, Wesson DM, Dujardin J-P, Beard CB 1999. Mitochondrial DNA sequence variation among triatomine vectors of Chagas' disease. Am J Trop Med Hyg 60: 377-386.

Moncayo A 2003. Chagas disease: current epidemiological trends after the interruption of vectorial and transfusional transmission in the Southern Cone countries. Mem Inst Oswaldo Cruz 98: 577-591.

Monteiro FA, Perez R, Panzera F, Dujardin JP, Galvão C, Rocha D, Noireau F, Schofield C, Beard CB 1999. Mitochondrial DNA variation of Triatoma infestans populations and its implication on the specific status of T. melanosoma. Mem Inst Oswaldo Cruz 94: 229-238.

Nei M, Tajima F 1981. DNA polymorphism detectable by restriction endonucleases. Genetics 97: 145-163.

Noireau F, Cortez MGR, Monteiro FA, Jansen AM, Torrico F 2005. Can wild Triatoma infestans foci in Bolivia jeopardize Chagas disease control efforts? Trends Parasitol 21: 7-10.

Panzera F, Dujardin JP, Nicolini P, Caraccio MN, Rose V, Tellez T, Bermudez H, Bargues MD, Mas-Coma S, O'Connor JE, Pérez R 2004. Genomic changes of Chagas disease vector, South America. Emerg Infect Dis 10: 438-446.

Pless M, Juranek D, Kozarsky P, Steurer F, Tapia G, Bermudez H 1992. The epidemiology of Chagas' disease in a hyperendemic area of Cochabamba, Bolivia: a clinical study including electrocardiography, sereoreactivity to Trypanosoma cruzi, xenodiagnosis, and domiciliary triatomine distribution. Am J Trop Med Hyg 47: 539-546.

Posada D, Crandall KA 1998. Modeltest: testing the model of DNA substitution Bioinformatics 14: 817-818. 
Schneider S, Roessli D, Excoffier L 2001. Arlequin ver 2.01: A software for population genetic data analysis. Genetics and Biometry laboratory, University of Geneva, Switzerland.

Schofield CJ 1988. Biosystematics of the Triatominae. In MW Service, Biosystematics of Haematophagous Insects, Clarendon Press, Oxford.

Schofield CJ, Dias JCP 1999. The Southern Cone initiative against Chagas disease. Adv Parasitol 42: 1-27.

Swofford DL 2002. PAUP*. Phylogenetic Analysis Using Parsi- mony (*and Other Methods). Version 4.0b10 Sinauer Associates, Sunderland, Massachusetts.

Torrico RA 1946. Hallazgo de Eratyrus mucronatus, infestación natural de "vinchucas" de cerro y Eutriatoma sordida en Cochabamba. Ann Lab Central de Cochabamba 1: 19-23.

Wincker P, Telleria J, Bosseno MF, Cardoso MA, Marques P, Yaksic N, Aznar C, Liegeard P, Hontebeyrie M, Noireau F, Morel CM, Breniere SF 1997. PCR-based diagnosis for Chagas' disease in Bolivian children living in an active transmission area: comparison with conventional serology and parasitological diagnosis. Parasitology 114: 367-373. 